\title{
Formação do indivíduo na cultura e seus limites no desenvolvimento brasileiro
}

\section{Waldecy Rodrigues ${ }^{1}$}

1 Pós Doutor em Economia (UnB), Doutor em Sociologia (UnB). Programa de Pós Graduação em Desenvolvimento Regional. Universidade Federal do Tocantins, Brasil. E-mail: waldecy@terra.com.br

RESUMO: O artigo tem como objetivo compreender como o processo de individuação na cultura brasileira vem se desenvolvendo historicamente e quais são seus rebatimentos sobre o desenvolvimento econômico e social brasileiro, por meio da análise específica de uma das representações coletivas fundamentais da sociedade: a formação religiosa. A abordagem hermenêutica que visa à percepção de fragmentos na vida cotidiana brasileira foi o eixo metodológico fundamental do trabalho. O catolicismo instaurado no Brasil pela instituição da escravatura e sua contradição com a liberdade e a igualdade cristãs não fixou fortes laços de hierarquia e de solidariedade no processo de individuação no Brasil colonial, e isso trouxe traços de desigualdade e inibição da solidariedade e da capacidade de iniciativa ao nosso modelo social e econômico.

Palavras-chave: cultura brasileira, cultura e desenvolvimento, religião e desenvolvimento.

Individual training in culture and its limits in the brazilian development

\begin{abstract}
The article aims to understand how the process of individuation in Brazilian culture has developed historically and their repercussions on the Brazilian economic and social development through the specific analysis of one of the fundamental collective representations of society: religious training. The hermeneutic approach aimed at the perception of fragments in Brazilian daily life was the fundamental methodological shaft work. Catholicism introduced in Brazil by the institution of slavery and its contradiction with freedom and equality does not set strong Christian hierarchy and solidarity ties in the individuation process in colonial Brazil, it brought inequality traits and inhibition of solidarity and capacity for initiative to our social and economic model.
\end{abstract}

Keywords: Brazilian culture, culture and development, religion and development.

\section{INTRODUÇÃO}

Este artigo busca compreender como o processo de individuação na cultura brasileira vem se desenvolvendo historicamente e quais são seus rebatimentos sobre o desenvolvimento econômico e social brasileiro, por meio da análise específica de uma das representações coletivas fundamentais da sociedade: a formação religiosa. Do ponto de vista conceitual, entende-se por individuação um processo histórico que denota como são formados sociologicamente os indivíduos de uma determinada cultura, com reflexos seminais sobre a formação das estruturas sociais e econômicas de uma sociedade. 
Como correlacionar a estrutura econômica brasileira com sua formação religiosa fundamentada no catolicismo, na magia e na escravidão? Sem dúvida alguma, esse é um ângulo muito interessante para se compreender a sociedade brasileira moderna, dada a grande relevância que o pensamento religioso tem sobre a formação cultural e econômica do Brasil. Nesta análise, o país é focalizado fundamentalmente como uma sociedade pertencente ao Ocidente, mas que, no contexto da cultura ocidental, ocupa uma posição peculiar, em que se percebem elementos do individualismo, da hierarquia e da magia primitiva na formação da individuação no processo social.

Primeiramente, é necessário abordar alguns conceitos e idéias fundamentais para o entendimento de cultura, de religião e do aspecto relacional destes com o processo de formação do indivíduo brasileiro. Ou seja, entender, no processo da formação da subjetividade dos indivíduos brasileiros, na formação de suas representações coletivas, qual é a influência dos fatores religiosos e como isso se tornou palpável na história.

Geertz (1978) coloca que o conceito de cultura denota um padrão de significados transmitido historicamente, incorporado em símbolos, um sistema de concepções herdadas expressas em formas simbólicas por meio das quais os homens comunicam, perpetuam e desenvolvem seu conhecimento e suas atividades em relação à vida. Conforme essa visão, os símbolos sagrados têm a função de sintetizar o ethos de um povo, ou seja, o tom, o caráter e a qualidade de sua vida, seu estilo e disposições morais e estéticas. A concepção de mundo de um povo é dimensionada por suas representações coletivas, ou seja, são nas formas mais elementares da vida cotidiana e nas idéias mais abrangentes sobre a sociedade que se podem perceber sinais da consciência coletiva.

No que concerne aos padrões culturais, isto é, aos sistemas ou complexos de símbolos, o traço genérico de primordial importância é que eles representam fontes extrínsecas de informação, ou seja, utilizando-se do instrumental durkheimiano, podese dizer que fazem parte da consciência coletiva das sociedades. Nesse sentido, as inclinações que os símbolos sagrados induzem, em épocas e lugares diferentes, vão desde a exultação até a melancolia, da autoconfiança à autopiedade, de uma alta determinação para a vida a uma suave apatia. Podem motivar um povo para o desenvolvimento social e econômico e, também, levar esse mesmo povo a um descrédito e à falta de motivação para se ver como uma nação que pode se realizar enquanto tal.

É importante colocar que nem todas as realizações culturais são realizações religiosas e a linha entre as que o são e as realizações artísticas, ou até mesmo políticas ou econômicas, não é muito fácil de ser demarcada na prática, pois, como as formas sociais, as formas simbólicas podem servir a múltiplos propósitos. Por isso, questiona-se uma abordagem tão cara ao pensamento científico ocidental que, geralmente, processa a compreensão do homem em esferas distintas - econômica, social, política e psicológica - sem inter-relação entre si. Neste artigo ter-se-á um posicionamento metodológico diverso do exposto anteriormente: será priorizado o aspecto relacional e 
totalizante do fenômeno social.

A religião é sociologicamente importante não porque descreve a ordem social, mas porque ela a modela, em fronteiras multidisciplinares, tal como fazem o ambiente, o poder político, a economia, as relações pessoais e o sentido estético. Por isso, é justamente pela avaliação do impacto dos sistemas religiosos sobre os sistemas sociais que se torna possível uma avaliação geral do valor da religião em termos tanto morais como funcionais.

Dada a extensão do tema, percebe-se a existência de diversas possibilidades de investigação para o objeto em questão. Entretanto, opta-se por uma abordagem que possa demonstrar sinais e trilhas para uma pesquisa mais ampla em um momento posterior. Nesse sentido, utiliza-se uma metodologia que possibilite uma hermenêutica histórica, compreendendo elementos estruturais da sociedade e, ao mesmo tempo, permitindo enxergar na interpretação dos sinais e fragmentos na vida cotidiana das pessoas como as matrizes religiosas influenciaram e influenciam o processo de individuação na cultura brasileira.

De início, será apresentada a base teórica para a investigação proposta. Serão discutidos modelos para a interpretação da modernidade, principalmente na compreensão das sociedades holistas e individualistas, com base nas contribuições do antropólogo francês Louis Dumont e do sociólogo alemão Nobert Elias, entre outros autores. Em seguida será enfocada a problemática na sociedade brasileira, principalmente abordando aspectos da formação histórica da cultura a partir da obra do sociólogo francês Roger Bastide, em que será destacado o processo de escravidão no país correlacionando-o com as matrizes religiosas da época, existentes no país: o catolicismo extremamente particular implantado no Brasil e as religiões africanas trazidas pelos escravos, que resultaram em um forte sincretismo religioso marcado por elementos mágicos. Por fim, numa abordagem mais contemporânea, será demonstrada a contribuição do antropólogo brasileiro Roberto DaMatta, que discute a formação da identidade do brasileiro, a partir de sinais e fragmentos, ressaltando importantes elementos para a compreensão do processo de individuação na moderna cultura brasileira.

\section{FORMAS DE INTERPRETAÇÃO DA MODERNIDADE}

No desenvolvimento de um projeto de antropologia da modernidade, Dumont (1992) estabeleceu dois modelos compreensivos: o das chamadas sociedades holistas e o das sociedades individualistas. No primeiro caso, observa-se uma dominância das formas coletivas e hierárquicas de existência social, em que a coletividade e suas tradições condicionam as existências individuais e limitam a possibilidade da formação de uma esfera íntima e privada na sociedade. Como exemplos de sociedades holistas, o autor cita as sociedades primitivas e a moderna sociedade indiana.

Quanto às sociedades individualistas, têm-se como exemplos as sociedades capita- 
listas modernas, nas quais as necessidades individuais se constituem no objeto o qual a sociedade modela suas estruturas de funcionamento. Eles são tomados como valor a ser realizado pelas práticas sociais, o que implica o estabelecimento de normas e ideais individualistas, cujo paradigma está explicitado no ideário liberal dos séculos XVIII e XIX. Entretanto, não como se falar em apenas um tipo ideal de capitalismo modelado por um único tipo de ética individualista, as relações entre sociedade e Estado, são modeladas pelas diversas naturezas das instituições que compõe o mosaico social.

Contudo, tanto a hierarquia - elemento fundamental das sociedades holistas como o individualismo - elemento fundamental das sociedades individualistas - devem ser vistos como estruturas flexíveis e não como modelos rígidos com dinâmicas completamente distintas. Nas sociedades holistas, por mais hierarquizadas que sejam, sempre vai existir um grau de individualização; e nas sociedades individualistas, por mais liberais que possam se tornar, sempre haverá, em certa medida, algum grau de hierarquização. Neste caso pode-se classificar em alguma medida a sociedade brasileira, na qual é quase impossível dizer onde começa o individualismo e onde começa a hierarquia, principalmente quando esses elementos são regados com uma boa dose de magia primitiva.

$\mathrm{Na}$ análise das sociedades ocidentais modernas, Figueiredo (1995) faz, do ponto de vista metodológico, uma útil distinção conceitual entre pessoas, sujeitos e meros indivíduos. $\mathrm{O}$ autor coloca que em toda coletividade estratificada há muitos lugares e, assim, muitas pessoas qualitativamente diferentes; há nas sociedades individualistas uma massa anônima de meros indivíduos, indiferenciados e intercambiáveis; há também, nessas sociedades, os sujeitos, que são os papéis definidos pela estrutura individualista.

Os sujeitos e os meros indivíduos configuram algumas possibilidades modernas de subjetivação da pessoa. Meros indivíduos gozam de uma precária e muito discutível interdependência de vínculos e obrigações - rompidas com a dissolução das instituições holistas -, mas ficam reduzidos à condição de objetos de uso alheio e submetidos a formas autoritárias de controle. Nesse sentido, percebe-se que nas sociedades individualistas, para sua própria reprodução, exige-se a permanência ou mesmo a criação de dispositivos pré-modernos que preencham a função de disciplina social para dar papéis sociais às pessoas.

Outra maneira bastante interessante de se compreender o processo de individuação na sociedade moderna é distinguir, como fizeram Durkheim (1996) e Dumont (1993), identidade e identificação. O conceito de identificação está associado ao sujeito empírico que fala, pensa e quer, ele mesmo sendo uma amostra individual da espécie humana encontrada em todas as sociedades. O conceito de identidade, por sua vez, não seria uma simples soma de identificações ou coleção de pessoas - nessa concepção, o indivíduo faz parte e tem sua vida dimensionada por um todo social, ou seja, o homem não pensa isoladamente, mas por intermédio de categorias engen- 
dradas pela vida social. Essas categorias seriam construídas pelas representações ideológicas, cabendo ao indivíduo ser obreiro dessa construção. As representações coletivas, ou seja, as ideologias, seriam produto de uma imensa cooperação coletiva, resultado de uma multidão de espíritos diversos que durante gerações acumulam experiência e saber.

Entender como o processo de individuação é realizado nas sociedades tem fundamental importância para este trabalho, na medida em que o principal objetivo aqui é discutir como uma forma particular de representação coletiva - as estruturas religiosas - influencia o comportamento social moderno. Elias (1994) proporciona uma séria reflexão sobre a consideração de que o processo de individuação é simplesmente determinado por elementos ditos "sociais". O autor coloca que, obviamente, todo indivíduo nasce num grupo de pessoas que já existiam antes dele, entretanto não se pode dizer que os seres humanos devem ser, exclusivamente, determinados pelo que Durkheim chamava de "multidão de espíritos diversos", nem, muito menos, como postulava o ideário liberal, para o qual o indivíduo era artífice incondicional do seu próprio destino.

Segundo Elias (1994), pode-se chegar a uma compreensão clara da relação entre indivíduo e sociedade quando se adota uma perspectiva híbrida e relacional do processo de socialização. Em outros termos: idéias, convicções, afetos, necessidades e traços de caráter produzem-se no indivíduo mediante a interação com os outros, como coisas que o seu "eu" mais pessoal e nas quais se expressa, está umbilicalmente intrincado com a rede de relações de que ele emergiu e na qual penetra. É a ordem desse entrelaçamento incessante e sem começo que determina a natureza e a forma do ser humano individual.

Mesmo que os argumentos de Elias (1994) sejam questionáveis, principalmente na sua tese central, de que o indivíduo é determinado pelas redes humanas através de forças históricas e caóticas, para este trabalho o autor oferece um ganho metodológico e epistemológico fundamental, na medida em que tece críticas pertinentes às formas tradicionais de compreensão sociológica: o individualismo e o holismo metodológico.

Ao se pensar a respeito da influência das matrizes religiosas brasileiras sobre o processo moderno de individuação, pretende-se percorrer os eixos da evolução histórica, principalmente ao se analisar o processo da escravatura relacionado com o catolicismo "brasileiro", as religiões afro-brasileiras e o sincretismo religioso.

Com base nessas reflexões, ter-se-á o cuidado metodológico de não se compreender os reflexos dessas formas religiosas sobre o processo moderno de individuação em termos absolutos. Não se considerando, dentro da própria estrutura cultural brasileira, alternativas históricas e acontecimentos que ocorrem meramente ao acaso. Nesse sentido, o eixo fundamental deste artigo será a abordagem hermenêutica que visa à percepção de fragmentos na vida cotidiana brasileira. 


\section{CATOLICISMO E MAGIA NO BRASIL COLONIAL}

Bastide (1971), através do método comparativo histórico, aplicando aquilo que ele chama de "sociologia em profundidade", fez um estudo sobre as religiões afrobrasileiras que se constituíram e continuaram sendo construídas em meio a profundas alterações da estrutura social. Abordou, de uma forma relacional, as religiões afro-brasileiras e as particularidades do catolicismo implantado no Brasil.

Os negros introduzidos no Brasil pertenciam a etnias diferentes e provinham das mais variadas regiões da África. Porém, suas diferentes religiões, quaisquer que fossem, estavam ligadas a certas formas de família ou de organização clânica, com rituais predominantes ligados à magia primitiva. Em alguma medida, o tráfico negreiro desestruturou as representações coletivas dos negros. E o escravo foi obrigado a se incorporar a um novo tipo de sociedade, baseado na família patriarcal, no latifúndio e no regime escravocrata. Salienta-se que o período de escravidão durou três séculos, dimensionando profundamente a memória e a consciência coletiva não só dos negros, mas de todos os brasileiros.

A sociedade brasileira foi se transformando lentamente até chegar ao processo de industrialização, e isso não deixou de repercutir e ser repercutido pelas matrizes religiosas brasileiras. Entretanto, o que importa por ora é que as manifestações religiosas dos negros sofreram dupla pressão cultural do Estado português e do catolicismo adotado no Brasil - sustenta-se a tese de que este tinha características bem diferenciadas daquelas do catolicismo romano. Esta dupla pressão fez com que as representações religiosas, como os símbolos da mística, os valores culturais dos africanos ou de seus descendentes se achem subordinados às representações coletivas dos cristãos, dos símbolos culturais europeus e dos valores portugueses.

Por outro lado, a cultura religiosa lusa foi importada também e não deixou, como a cultura religiosa africana, de sofrer influências a partir de um processo de desestruturações e reestruturações da sociedade brasileira em formação. A religião católica dominante sofreu a influência das transformações da estrutura social, ela, de outro lado, moldou a nova sociedade; encarnou-se nela como uma alma que, de dentro, modelaria o corpo onde passaria a viver.

Portugal importa sua sociedade ao mesmo tempo em que sua civilização. A escravidão, pelo contrário, submete a sociedade africana, com seus valores e representações. Entretanto, do lado português, as novas condições de vida baseadas no latifúndio por exploração, inviabilizam a povoação tipicamente portuguesa com seu rico folclore, seus grupos de vizinhança, seus bens comunitários, seus hábitos de ajuda recíproca e de cooperação vicinal, sua solidariedade em torno da igreja paroquial.

O dito de Padre Vieira (1995), que como bom português e católico espantou-se diante do processo de ocupação fundiária em grandes latifúndios permanece válido: " $E$ cada família chega a ser uma República". De fato, ao lado do senhor de engenho, ou do senhor do gado, agrupam-se todos aqueles que vivem à sombra da casa-grande, o 
que foi tão bem retratado por Gilberto Freyre em sua obra Casa-grande e senzala.

A solidariedade manifesta no Brasil não repousa sobre o trabalho comunitário, sobre a cooperação democrática, e sim sobre o trabalho escravo, a servidão dissimulada dos mestiços e a hierarquia familiar. As formas orgânicas de manifestação dessa solidariedade eram representadas nas formas de compadrio; o laço religioso juntouse ao laço da dependência econômica ou social para corrigi-lo, para dar-lhe uma coloração afetiva e sentimental que não tinha em sua origem.

O catolicismo implantado no Brasil é originário da Contrarreforma, que em oposição ao protestantismo, desperta o velho culto aos santos e, por isso mesmo, ressuscita em parte as superstições da Idade Média. Sem dúvida, nas grandes plantações de cana-de-açúcar há um capelão, que poderia ser o representante da Igreja, o mantenedor da herança religiosa européia. Entretanto, ele geralmente é remunerado pelo senhor de engenho, e sua nomeação, em muitos dos casos, veio de Lisboa, devido à instituição do padroado no século XVI, e não de Roma. Porém, houve uma importante exceção, representada pelas ordens religiosas que mantinham estreitos vínculos com as tradições do catolicismo romano. No caso brasileiro, houve a presença marcante da ordem jesuíta, agente participante de alguns conflitos com a ordem colonial portuguesa.

O processo de adaptação das etnias e religiões africanas se deu a partir de processos sincretismos mais ou menos profundo como cristianismo. Relata-se que o catolicismo brasileiro era bastante diferente do catolicismo europeu, pois nosso catolicismo mantinha uma relação profunda com a escravidão e com o modelo latifundiário. O escravo entrava nesse ritmo cristão ao lado do branco, mas sempre numa posição subordinada: ele fazia parte da comunidade doméstica enquanto comunidade religiosa, mas como um ser inferior e como propriedade do senhor. Em suma, a estrutura da família patriarcal escravista inibia o igualitarismo cristão e se opunha ao desenvolvimento de um senso de igualdade e fraternidade horizontal entre as pessoas, independentemente de sua raça ou condição social.

Eis um dos pontos fundamentais deste artigo, o de saber qual foi o tipo de religiosidade que dimensionou a formação social brasileira. O catolicismo instaurado no Brasil, seja pela instituição da escravatura e sua contradição com a liberdade e a igualdade cristãs, seja pela submissão de quase toda Igreja Católica ao império português pela instituição do padroado, basicamente não fixou fortes laços de hierarquia e de solidariedade no processo de individuação no Brasil colonial.

Tanto os negros como os índios, que tinham suas manifestações religiosas associadas à magia primitiva, viram seus valores e seus "deuses" ser derrotados pela "cruz" dos dominadores. Assim, em grande parte, a reação mágica dos dominados foi a de adaptar-se à nova realidade.

Contudo, como os valores hierárquicos e de solidariedade do catolicismo não conseguiram fixar-se por completo na consciência coletiva brasileira, em virtude da escravidão e do padroado, criou-se uma espécie de sentimento de "derrota mágica", 
em que se estabeleceu uma espécie de mana baseado em sentimentos profundamente arraigados no processo de individuação do brasileiro: derrota, medo, ressentimento e ódio.

O sincretismo religioso e a miscigenação de raças, em boa medida, guardam a capacidade adaptativa do brasileiro, mas no fundo esse processo representa que houve a derrota de um modelo civilizatório por outro, a subjugação de um modelo religioso por outro. Entretanto, a magia não está presente necessariamente em uma igreja por seu caráter plástico, ela se manifesta de várias maneiras na sociedade - e, como o catolicismo não conseguiu implementar seus valores fundamentais, o sentimento de "derrota mágica" passou a permear a essência do indivíduo brasileiro.

\section{FRAGMENTOS DA IDENTIDADE BRASILEIRA MODERNA}

Ao abordar aspectos históricos e cotidianos sobre o processo de individuação no Brasil, DaMatta (1997) coloca que a idéia romântica da miscigenação das raças é um equívoco histórico. Quando se acredita que o Brasil foi feito de negros, brancos e índios, está se aceitando sem muita crítica a idéia de que esses contingentes humanos se encontraram de modo espontâneo, numa espécie de "carnaval" social e biológico.

Mas nada disso é verdade. $O$ fato contundente da história brasileira é que o país foi feito por portugueses brancos e aristocráticos, uma sociedade hierarquizada que foi formada dentro de um quadro rígido de valores discriminatórios. A mistura de raças foi um modo de esconder a profunda injustiça social contra negros, índios e mulatos, pois, situando no biológico uma questão tão profundamente social, econômica e política, deixava-se de lado a problemática mais básica da sociedade, que é enfrentar suas contradições e desigualdades.

É mais fácil dizer que o Brasil foi formado por um triângulo de raças, o que conduz ao mito da democracia racial, do que assumir que se trata de uma sociedade extremamente discriminatória que opera por meio de gradações e que, por isso mesmo, pode admitir uma série de categorias entre o branco superior e o negro pobre inferior. Assim, pode-se, magicamente, situar as pessoas pela cor da pele ou pelo dinheiro: por seus pais e o nome de família, ou por sua conta bancária. O sentido de "derrota mágica", com uma hierarquia pouco definida, proporciona adaptativamente várias possibilidades de discriminação social.

Ainda para DaMatta (1997), os brasileiros marcam certos espaços como referenciais da sua sociedade. A casa, onde mora, come e dorme. A rua, onde trabalha e luta pela vida. A esses espaços, onde se convive com parentes, amigos e colegas de trabaIho, deve-se somar outro, não menos importante. Trata-se do espaço do outro mundo, essa área demarcada por igrejas, capelas, ermidas, terreiros, centros espíritas, sinagogas, templos, cemitérios e tudo aquilo que faz parte e sinaliza as representações religiosas.

A variedade das experiências religiosas brasileiras na contemporaneidade é, ao 
mesmo tempo, ampla e limitada. É ampla porque, ao catolicismo romano e às várias denominações protestantes, somam-se outras variedades de religiões ocidentais e orientais, além das variedades brasileiras de cultos de possessão e de diversas matrizes do espiritismo. Mas é limitada porque, em todas as formas de religiosidade brasileiras, há uma enorme e densa ênfase na relação deste mundo com o outro, de modo que a domesticação da morte e do tempo é elemento fundamental em todas essas variedades e jeitos de se chegar a Deus.

Assim como temos pais, padrinhos e patrões, temos também entidades sobrenaturais que nos protegem. E elas podem ser de duas tradições religiosas aparentemente diferentes, mas isso realmente não importa. O que para um norte-americano calvinista, um inglês puritano ou um francês católico seria sinal de superstição e até mesmo de ignorância, para os brasileiros é a maneira de se aumentar a possibilidade de proteção. Isso se deve à grande força que a magia primitiva tem sobre a formação da consciência coletiva, dimensionando o processo de individuação do brasileiro.

O que pode parecer singular no caso brasileiro, devido à forte presença da magia primitiva, é que cada uma dessas formas de religiosidade seja suplementar às outras, mantendo com elas uma relação de plena complementação. Ao lado de formas impessoais, mais politizadas ou socialmente aceitas do comportamento religioso, podem-se encontrar formas mágicas e pessoais de ligação com o outro mundo, como o milagre ou as mudanças mágicas no estado de vida dos indivíduos.

\section{CONCLUSÕES}

No Brasil, a interação entre o moderno e o tradicional, entre o holístico e o individualista, é mediada por elementos oriundos da magia primitiva. Não obstante, essa noção do uso do ethos em função de interesses particulares, ou seja, de que o indivíduo brasileiro não se vê necessariamente ligado a valores holistas ou individualistas, é determinada por ambos de uma forma não muito bem definida. Esse indivíduo tem uma grande capacidade de adaptação às situações que a vida lhe oferece, tanto condições propícias como adversas, e isso, em alguma medida, lembra aspectos do processo de individuação nas sociedades fundamentadas na magia primitiva.

Trata-se geralmente de um indivíduo plástico e disposto a se adaptar a qualquer circunstância que a vida Ihe oferece. O indivíduo brasileiro, geralmente, mantém uma relação aparentemente dúbia com as normas e leis que gerem a sociedade, prefere a lei do sucesso instrumental a qualquer preço e sem limites, conhecida entre nós como a "Lei de Gerson". Prefere transformar sua vida, por algum passe de mágica, em vez de lutar na construção de algum ideal coletivo.

Como reflexão particular, questiona-se como a formação religiosa brasileira pode ser considerada um elemento dimensionador da nossa estrutura econômica. O sistema capitalista encontrou no Brasil, como em poucas partes do mundo, as condições mais adequadas para realizar sua essência. A realização do ciclo do capital não viu, do 
ponto de vista religioso, nenhum empecilho para sua completa realização. Aqui o capitalismo poderia se desenvolver da forma que bem compreendesse, "preferiu" ser primário exportador, baseado na economia dos ciclos e o foi por mais de quatro séculos.

Pode-se compreender a estrutura econômica e política brasileira considerando-se que, historicamente, há um capitalismo dependente e periférico e, até o século XIX, escravista. Formado por uma elite de proprietários rurais - econômica e culturalmente dependente dos procedimentos, normas e valores metropolitanos -, uma massa de escravos e outra, em crescimento constante, de homens livres e pobres. As relações entre senhores e escravos são regidas predominantemente pela lógica capitalista do lucro e do uso. Já as relações entre homens livres e pobres estão submetidas a uma dupla lógica: a lógica racional e econômica que privilegia o desempenho, a competência e o mérito individual, e a lógica do favor, do apadrinhamento e do clientelismo.

No Brasil, já faz muito tempo que se busca um modelo autônomo de desenvolvimento social e econômico. Políticas sociais e econômicas vêm sendo pensadas e aplicadas constantemente ao longo de nossa história. O Brasil só vai começar efetivamente a se desenvolver social e economicamente quando começar a se enxergar como nação, construindo novas representações coletivas capazes de redimensionar o processo de individuação.

Nessas eventuais olhadelas para o interior de sua consciência coletiva, certamente vai ser encontrada a "derrota mágica" vivida no Brasil colônia, e o nosso mana - derrota, medo, ressentimento e ódio - será, conseqüentemente, mais bem visualizado. Estes elementos produzem uma sociedade profundamente desigual e que em muitos momentos não acredita que pode ser capaz de superar suas contradições. Assim, para o Brasil de fato avançar em seu processo de desenvolvimento, é relevante que estas representações coletivas sejam percebidas e consideradas nos processos de socialização dos indivíduos.

\section{BIBLIOGRAFIA}

BASTIDE, Roger. As religiões africanas no Brasil. São Paulo: Pioneira, 1971. COSTA, Jurandir Freire. Narcisismo em tempos sombrios. In: BIRMAN, Joel. Percursos da história da psicanálise. Rio de Janeiro: Taurus, 1988.

DAMATTA, Roberto. O que faz o Brasil, Brasil? Rio de Janeiro: Rocco, 1997.

DUMONT, Louis. Homo Hierarchicus. São Paulo: Edusp, 1992.

O individualismo: uma perspectiva antropológica da ideologia moderna. Rio de Janeiro: Rocco, 1993.

DURKHEIM, Émile. Formas elementares da vida religiosa. São Paulo: Martins Fontes, 1996.

ELIAS, Norbert. A sociedade dos indivíduos. Rio de Janeiro: Zahar, 1994. 
FIGUEIREDO, Luís Claudio. Modos de subjetivação no Brasil e outros escritos. São Paulo: Escuta, 1995.

FURTADO, Celso. Formação econômica do Brasil. São Paulo: Companhia Editora Nacional, 1989.

GEERTZ, Clifford. A interpretação das culturas. Rio de Janeiro: Zahar, 1978.

SOARES, Luiz Eduardo. O rigor da indisciplina. Rio de Janeiro: Relume-Dumará, 1994.

VIEIRA, Padre Antônio. Escritos históricos e políticos. São Paulo: Martins Fontes, 1995.

Artigo recebido em 11 de dezembro de 2016.

Aprovado em 01 de agosto de 2017. 